\title{
Re-Thinking the Boundaries of the Focus Group: A Reflexive Analysis on the Use and Legitimacy of Group Methodologies in Qualitative Research
}

\author{
by Martina Angela Caretta and Elena Vacchelli
}

Stockholm University; Middlesex University

Sociological Research Online, 20 (4), 13

<http://www.socresonline.org.uk/20/4/13.html>

DOI: $10.5153 /$ sro.3812

Received: 14 Apr 2015 | Accepted: 21 Sep 2015 I Published: 30 Nov 2015

\begin{abstract}
This article aims at problematizing the boundaries of what counts as focus group and in so doing it identifies some continuity between focus group and workshop, especially when it comes to arts informed and activity laden focus groups. The workshop ${ }^{[1]}$ is often marginalized as a legitimate method for qualitative data collection outside PAR (Participatory Action Research)-based methodologies. Using examples from our research projects in East Africa and in London we argue that there are areas of overlap between these two methods, yet we tend to use concepts and definitions associated with focus groups because of the lack of visibility of workshops in qualitative research methods academic literature.

The article argues that focus groups and workshops present a series of intertwined features resulting in a blending of the two which needs further exploration. In problematizing the boundaries of focus groups and recognizing the increasing usage of art-based and activity-based processes for the production of qualitative data during focus groups, we argue that focus groups and workshop are increasingly converging. We use a specifically feminist epistemology in order to critically unveil the myth around the non-hierarchical nature of consensus and group interaction during focus group discussions and other multi-vocal qualitative methods and contend that more methodological research should be carried out on the workshop as a legitimate qualitative data collection technique situated outside the cycle of action research.
\end{abstract}

Keywords: Focus Group Discussion, Workshop, Participation, Feminist Critical Research

\section{Introduction}

1.1 The focus group discussion (FGD) is a relatively recent qualitative data generation tool within the social sciences, and it has gained increasing of popularity since it was first discovered in the 1940s. From the 1990s onwards the FGD has acquired a more central position among recognized qualitative data collection techniques (Morgan et al. 2008; Chiu 2003). Yet FGDs have grown to imply many different activities and modalities of operationalization that are rarely discussed in academic literature (Hennink 2008). FGDs are undergoing a progressive hybridization i.e. the use of prompt activities, photo elicitation techniques and other art-informed strategies to stir the group conversation (Colucci 2007; Cooper and Yarbrough 2010; Silverman 2013). This article therefore critically looks at the increasing hybridization of the FGD throughout the social sciences by considering both the process by which qualitative data is generated and the kind of data collected through a moderated group discussion. This reflection was sparked by a consideration of the pitfalls and the potentials we encountered while employing this method in our respective research projects. When conducting fieldwork and analyzing our fieldwork processes and data we found that several characteristics exhibited in the FGD literature did not conform to our experiences of conducting FGD using prompts and art-based approaches in different contexts. To which extent were we really conducting FGDs and what is the difference between a FGD and a workshop when doing research outside a specifically PAR (Participatory Action Research) setting? 
This paper stems from listening to each other's works at a recent conference and questioning whether the set of activities we carried out with participants in our research projects fall in the realm of FGDs according to the way we originally defined them. The methods that we initially defined as FGDs point to a continuity with the workshop (WS) method, whose processes and data collection outcomes are under-represented and not sufficiently theorized in the qualitative research literature. We envisaged our qualitative data collection methods as FGDs rather than WS because this is the vocabulary we are more familiar with, which finds ample legitimization and is more extensively defined in the literature. By looking at several qualitative research manuals for the social sciences and conducting a preliminary on-line search, it became evident that while the FGD is abundantly discussed among qualitative data collection tools, there are strikingly fewer references to the WS in academic books, journals and outlets. This article points to the marginalization of the WS as a legitimate method for qualitative data collection outside a specifically PAR (Participatory Action Research) framework, highlights an increasing convergence between FGD and WS and problematizes the changing boundaries of what counts as FGD.

1.3 While our respective research projects stem from two social sciences disciplines i.e. human geography and social policy and are rather different fields of inquiry - i.e. mapping climate, labor and landscape interactions in small holder irrigation farming in the dry-lands of Eastern Africa and evaluating migrant, refugee and asylum seeking women's access to community-based mental health services in London - they are both grounded in a feminist epistemology. The methods we employ in our respective research aim at listening to research participants' perspectives, acknowledging their experiences in our own work. Moreover we devised a research design which reflects what we thought are effective ways for working with sensitive issues while at the same time grappling with the contentious issue of reciprocity between researchers and participants during the research process, focusing in particular on the moment when data are 'obtained' from the research participants. We also aimed at starting a reflexive process that might have a positive impact on research participants' everyday life. In order to bring forward these experiences, we made use of several hands-on activities to stimulate research participants' reflections on their daily practices as specified in the section on our respective research. According to our feminist research ethics, we feel uncomfortable with the idea that it is up to the researcher to empower research participants. Instead, we acknowledge research participants' personal power in their own life context and we ask how can we make this evident, how we negotiate our own and research participants' own power in the research relationship (see also Janes 2015).

1.4 Our studies were designed with the additional aim of being beneficial to the participants and providing them with some concrete tools that they could use and develop further. Martina's project for instance produced a booklet summarizing the overall interdisciplinary research findings together with numerous pictures to be presented in a 10 day final workshop between the two research sites. Elena chose an art-informed data collection approach, collage making, as a way to start a reflective journey for her research participants. Collage making is non-linear, draws on memory in a contained environment where the research participant can take time to express ideas, feelings and facts and also provides the setting to actually think about and make choices on how the contents can be communicated. Research participants were also given the choice to exhibit their work in the context of events organized by the women's organizations where the FGDs took place and eventually keep their work if they wanted to.

1.5 In this paper we offer a comparative definition of FGD and WS by highlighting the ways in which these two methods increasingly converge especially with regards to the kind of processes they require in order to generate data able to acknowledge the kind of intersectional differences that are performed during the different research events. However the ways in which group discussions happen and therefore the kind of data generated by the two research processes presents some differences that will be unpicked in the discussion section. We start by defining these two concepts as highlighted in the literature. We then outline examples from our own research projects to demonstrate the areas of continuity, highlight critical points and reflect on the shifting boundaries between the two methods.

\section{Focus group discussion}

2.1 Historically focus groups were first used by the sociologists Robert Merton and Paul Lazarsfeld to assess war time propaganda through group interviews with radio listeners in the 1940s (Kamberelis \& Dimitriadis 2013). However, since then they were mainly used in market research to assess consumers' attitudes to particular products. In the 1990s David L. Morgan (1997) 'rediscovered' the focus group as a social research tool. The key features of the focus group identified by Morgan include that (i) it should involve a group of people who discuss a given topic within a limited period of time; (ii) focus group participants may be known to each other or 
be strangers; (iii) as far as possible the conversations should be free flowing and have limited input by the moderator. The focus group is often referred to in the literature as Focus Group Discussion (FGD) as a way to emphasize that the goal of the preparatory exercises during a FGD is to elicit the discussion that follows. When organising a focus group, increasingly researchers make use of some sort of elicitation material such as pictures, newspaper articles, video clips or other cultural artefacts. Colucci (2007) for instance argues that exercises during the focus group are beneficial for more reflective participants and are particularly suited for discussing sensitive topics.

In the context of creative or activity-based focus groups, we understand the FGD as composed of two main stages: firstly, the preparatory and elicitation phase when material or suggestions for activities are laid out with the aim of creating a small group interaction in the form of a plenary discussion or further groups activities that trigger more and differently organised discussion flows, and, secondly, the actual interaction between participants in the form of a facilitated group discussion. While the first part is led by the researchers, at times just by making use of a simple FGD topic guide which was carefully prepared in advance, the second part is led by the research participants although still moderated by the researcher. Moreover, this two-stage process requires that the elicitation techniques and pre-discussion activities are acknowledged when it comes to analysing the qualitative data originating from the FGD.

2.3 In recent times the FGD has moved from peripheral to centre stage of qualitative research mainly for its effectiveness in terms of time and resources required (Jowett and O'Toole 2006) although one needs to acknowledge the substantial difference existing between data collected during a FGD and one-to-one interviews. Recent scholarly work (Marková et. al. 2007) highlights the dialogic nature of FGDs, emphasizing its performative character in that research participants manage to transform social knowledge when they talk and think together. This aspect of the FGD has been particularly praised by a range of feminist scholars for being contextual and non-hierarchical. It has been argued that the main advantage of a FGD is that it gives researchers a diversity of opinions during group interaction and reveals how collective sense is made (Merryweather 2010; Madriz 2000; Wilkinson 1999; Kitzinger 1994). Nevertheless it should not be implied that focus groups are inherently participatory methods because a group is convened. Due to gender, social status and other intersectional dimensions of the participants' identity, including specific positionalities and power relations existing in the group, some might not feel at ease to share their thoughts and some voices might prevail over others. The need for achieving consensus, which is among the aims of most FGD activities, tends to inhibit a healthy and constructive multivocality where diversity of opinions is stimulated and valued as inherent richness of the data as highlighted in a range of sociological literature (Merryweather 2010; Callaghan 2005; Baker and\& Hinton 1999; Catterall and Maclaren 1997).

2.4 Kamberelis and Dimitriadis (2013) also point to the collective element of FGD communication however the role of the moderator remains central in legitimising every participant's positionality in the group. The role of the moderator is of key importance in that $s /$ he has to make sure that the dialogue encourages diversity of opinions without aiming for consensus of opinions by overly agreeing with particular viewpoints expressed during the FGD. Agreeing with some viewpoints rather than others might have the undesirable effect of inhibiting those participants who might feel unable to speak as they suspect that the moderator will not share their perspectives and opinions. Moderators might have their hidden agendas and researchers might want to fulfill their expectations through the FGD. Hence, the implicit participatory and non-hierarchical character of FGDs should be reflexively questioned according to pre-existing power relations in the group, role of the moderator, research agenda and context in which the data is produced. Dominant voices might skew the discussion and in turn other voices might be silenced. Groups' power hierarchies are in fact reproduced especially in a context where all participants know each other (Merryweather 2010; Baker and\& Hinton 1999).

\section{Workshop}

3.1 The Workshop (WS) is defined by the Cambridge dictionary (2015) as 'a meeting of people to discuss and/or perform practical work in a subject or activity' and by Merriam Webster dictionary (2015) as 'a class or series of classes in which a small group of people learn the methods and skills used in doing something'. In sociology this method has been employed in the form of the "organization workshop": a large scale community empowerment approach which, through vocational courses, provides farmers in Southern Africa and Latin America with community organizational, literacy and time management skills (Labra \& Labra n.d.). Hence, the WS is a learning instance (see also Moschitz \& Home 2014). The dictionary definitions do not state however if there is any internal hierarchy in the group, if there is someone teaching and someone learning. It appears nevertheless to implicitly assert that there should be a person leading such gathering. 
WSs are employed predominantly as methods in participatory action research (PAR) in the global south, but it has not been developed as a data generating method outside PAR. From the ways in which FGDs are increasingly hybridized, the boundaries between the FGD and the WS are less and less clear. WS is a tool used in PAR (Participatory Action Research) aiming at democratizing access to research by involving participants in shaping the research aim and in taking stock of results to improve local conditions (Reid \& Frisby 2008). Hence, while it is true in the operationalization of the WS that a moderator needs to be present, WSs in PAR are prevalently left in the hands of participants. Participants are treated as experts in the topic under examination and the WS is an instance where they can share their knowledge, questions, concerns and ideas. Reciprocal learning is thus the crux of this tool, which ultimately seeks to initiate change through participants' reflection and sharing (Moschitz \& Home 2014; Chambers 2002). Outside PAR, the WS shares some of these characteristics except that research participants are not directly involved in shaping the research aims and the kind of change which is initiated during a workshop is not reinforced through cycles of feedback, reflection and action as it happens in PAR.

3.3 In the WS there is a moderator who mostly plays a role in starting off different types of exercises and activities which the participants have to carry out in group without the assistance and supervision of the moderator. Chambers (2002) discusses the use of workshop in PAR and goes as far as saying that WS should be used to 'empower the group and disempower yourself' (p.133) as a moderator. Common WS activities include: brainstorming, role playing, collage, sorting of picture, ranking usually with the help of stimulus material as pictures, flipcharts, posters, project plans and so on (Chambers 2002). WSs are also often used for scenario planning: hence, participants are given a future perspective to frame their thinking (i.e. Oreszcyn \& Carr 2008).

PAR, and with it the tools that it employs, has been criticised for being excessively empiricist and lacking theorization and hence legitimacy in academic domains. Accordingly, WSs as data collection tools have been idealized for producing just and equitable outcomes without examining the power dynamics existing between moderator and participants. The role of the moderator remains central in making sure that the discussion does not become conflictual or that it gets derailed. The goal with a WS is for participants to reach an agreement by the end of the activities and draw either a plan for change or to summarize what they learnt during these activities. However, like in the case of the FGD, it has been eloquently highlighted that the promotion of consensus can equate to suppression of conflict and diversity, especially when it comes to gender diversity, hence excluding some voices, which is opposed to what participation should be (Kapoor 2002). Even in the context of PAR, the WS has been criticized for lacking theoretical rigor and legitimacy. In this article however we argue that the WS can be a valuable tool for gathering insights into research participants' experiences especially when dealing with sensitive issues and when drawing on collective learning.

\section{Focus-shop or work-group?}

4.1 In this section we present our research projects focusing in particular on the qualitative data collection techniques we employed in our research projects in East Africa and in London. By critically looking at the processes we set up during fieldwork, we assess the extent to which our initially devised research design strategy, i.e. using FGDs for our respective research projects, reflects the current definitions of this data collection method. In doing so, we problematize the boundaries of the FGD and posit its continuity with the WS.

\section{Hydropatriarchies in East Africa}

In her PhD in human geography Martina has been investigating the current developments of two smallholder irrigation farming systems in East Africa - Tot, Kenya and Engaruka, Tanzania. Both are located in dry-lands and have ancient gravity irrigation systems which have been subjected to historical and archeological studies, but have not been investigated for their current developments. The aims of Martina's work were to examine (i) whether distinct patterns of gender labor dynamics imply different perceptions of climate variability, which in turn is reflected in gendered forms of adaptation to climate variability (see Caretta \& Börjeson 2015), and (ii) gendered practices of landscape formation (see Caretta 2014). The research also aimed to explore the role of local agricultural knowledge in the development and sustainability potential of these two smallholder irrigation farming systems. Martina's research was part of a bigger interdisciplinary project, which involved soil and water sampling. Hence, the qualitative data gathered in the field were also analyzed in relation to quantitative data sampled by her colleagues. weeks fieldwork in January and February 2012. These groups were gender and age specific and were made up 
Participants to the FGDs were selected by research assistants according to age, gender and occupation criteria. In fact, since the questions of the focus groups revolved around agricultural practices, crops and climate variability all had to be active farmers. Since both communities were quite small, all participants knew each other beforehand. That FGDs participants know each other might have hindered everyone's participation because of internal power hierarchies due to age and social status (cf. Merryweather 2010; Baker \& Hinton 1999). Nevertheless, this dimension was at least partially counteracted by the fact that groups were gender segregated and moderators were of the same gender of participants. Similarly it could be argued that moderators had their own interest in providing the researcher with a certain data (cf. Baker \& \& Hinton 1999). Martina strived to avoid this situation by employing two moderators of the same gender that would lead half of the activities each, in order to circumvent a single person's bias or participants 'possibly negative opinion of the moderator.

Focus groups literature (Krueger \& Casey 2008; Morgan 1997) recommends carrying out focus groups in the mother tongue of the participants to minimize the risk for error, misunderstandings and also to be more time effective. The literature (Hennink 2008; Barbour \& Flick 2007) indicates that richer material is gathered in participants' mother tongue and suggests to train someone else to moderate the FG when the researcher has limited language skills and knowledge of the local culture. Martina trained her research assistants to be moderators. They were tri-lingual (English - Swahili - local language), respected in the local communities, had already collaborated with other researchers and had good interpersonal skills. Thus, research assistants were trained on how to carry out activities autonomously for a couple of afternoons before starting (see also Caretta 2015).

4.6 FGDs were most often carried out outdoors in the shade of a tree sitting on rocks or on the ground while refreshments or a small compensation were provided to participants. As a meeting in an office or around a table can be perceived as formal in the local context, it was preferred to keep it informal and create a comfortable environment for participants (cf. Jakobsen 2012).

4.7 The FGD began with Martina introducing herself in Swahili and describing the activities that were to be conducted. During FGD Martina sat in the back or in the distance from the circle where the activities were taking place and practically observed participants' interactions from afar. While it could be argued that FGDs were double supervised by Martina and the moderator, participants were often so focused on their activities that they forgot that she was there. Whereas Wilkinson (1998) states that the power imbalance between participants and researcher is often challenged by the numeric majority of participants, in international settings the researcher's positionality can be a game changer (Liamputtong 2011). The risk is for instance that participants give the answer that they think the researcher wants to hear and that the FGD becomes a group interview rather than a dialogue among participant (Jakobsen 2012). Aware of these aspects, Martina instructed moderators to carry out activities which required minimal interventions from their side and which were inherently hands-on.

4.8 Group activities conducted during the FGD included: i) drawing on a flip chart an agricultural calendar, the timeline of the last 30 years with remarkable weather events; ii) ranking the best year during the last decade in terms of yields and iii) participatory mapping on a satellite picture and mapping irrigation canals.

4.9 All FGDs were recorded and transcribed with the help of the assistants (for a detailed analysis of language and power dynamics see Caretta 2015). At the beginning of every FGDs, Martina asked for permission to record the meeting and she opened up for questions from the participants in an attempt to trigger nonhierarchical exchange as prescribed by feminist epistemology. Often participants did not have questions at the beginning, but at the end the discussion would become much longer than expected because they became curious about Martina's research project and they asked for suggestions on how to improve their agricultural practices. Martina had to reiterate several times that she was no agricultural officer, but only a PhD student. Picking up on their drawings or on their practices, she asserted their farming expertise, as they had productively cultivated for centuries without the use of any additive. In the spirit of reciprocal learning and dialogical exchange, Martina openly communicated her thoughts and showed her attitude towards the upcoming external agricultural investments (cf. Liamputtong 2011). There were hence two types of data generated. On one hand, data on agricultural practices in forms of charts and maps which Martina used in her research process; on the other hand, transcripts of the discussions taking place at the end of group activities constituted data on the topic of knowledge exchange and reciprocal positionality among researcher and participants. The latter type of data is rarely discussed in the literature, according to Baker and Hinton (1999). 
4.10 Participants shared their knowledge through the proposed activities and engaged with Martina to somehow test their understanding and improve their knowledge. They sounded doubtful about their own practices and wanted to enhance their agricultural productivity thinking that Martina was an expert and could provide them with new insights. In those instances which manifested the power imbalance between researcher and participants, Martina saw an opportunity to create awareness among participants of their own knowledge (cf. Chiu 2003) and encouraged them to trust more in their own judgment rather than in the grand plans and technological fixes promised by NGOs or the government. Especially when women voiced their powerlessness in autonomously deciding about water management or in intra-household relations, it was evident that these activities had created a space for interaction and solidarity between women that did not exist before, in line with our feminist epistemological grounding (Kamberelis \& and Dimitriadis 2013). Strictly speaking these dynamics would have not taken place in a FGD where the moderator follows a discussion guide and leads the conversation according to that. On the other hand though recent literature on FGD encourages the use of "open-ended prompts allowing participants to direct conversations" and highlights that FGD can mean different things to different researchers (Kamberelis \& Dimitriadis 2013:70). WS is centered on learning both reciprocal and guided by a moderator. When at the end of the group activities, which were aimed at triggering reciprocal learning among participants, Martina opened up for discussion, participants' questions prompted yet again another learning process this time with the inclusion and guidance of Martina. She could revisit the charts they had just created to show them the insightfulness and expertise intrinsic in the mix and timing of different crops and agricultural practices. These were aspects that external agricultural experts would not have been able to advise farmers about as they would not know soil characteristic, water availability and traditional seeds features. However, as these discussions took place at the end of group activities, Martina's opinions did not have implication on the data generated on agricultural practices. Hence, knowledge among participants was constructed by triggering reflections on the practices they were using which first led to contrasting views, secondly to negotiation of meaning and lastly to self-awareness.

\section{Accessing community-based mental health services in London}

4.11 Elena recently conducted a project aimed at assessing existing provision of mental health services available to refugee, asylum seeking and migrant women in London, in collaboration with a local refugee organization which was pivotal in assisting and co-organizing data collection. Migrant and BMER (Black, Minority Ethnic and Refugee) women in reproductive age and the barriers they experience when trying to access health services have been one of the foci of the comparative European Fundamental Rights Agency project Inequalities and multiple discrimination in access to and quality of healthcare coordinated by the Middlesex University team where Elena is currently based. As part of creating a local impact for this major international comparative project, the project in London attempted at mapping community based mental health service provision and other specific services that refugee women access in relation to perinatal problems and extend to traumatic experiences to include Domestic Violence and FGM. Apart from mapping service provision in these areas, the project assessed barriers to access to mental health services that asylum seeking and refugee women in reproductive age experience across London.

4.12 The project team devised a mixed method approach in order to capture quantitative aspects of the mapping and include both opinions and experiences of community organizations practitioners and experiences in accessing mental health services from the migrant women themselves. In particular, the survey aimed at gathering a mix of qualitative and quantitative data through the use of both open and closed questions, consisting of on-line questionnaires to community organizations in London with a focus on mental health. The research design also comprised of three participatory workshops with community practitioners from women organizations offering mental health services; a series of semi-structured interviews with available practitioners who were happy to share their experiences of working with mental health; two creative FGDs with refugee and asylum seeking women who normally access group therapy. In the last instance, collage making was used to elicit research participants' life narratives and their experiences of accessing community based mental health services, see Vacchelli et al (forthcoming ) and Vacchelli (forthcoming). The use of the creative FGD in this project contributed to raise the set of questions informing this paper.

4.13 When planning the focus groups, Elena was mindful of the vulnerable nature of most research participants' circumstances and made sure to carefully explain to the groups the aims of the research, offer a safe space where boundaries of the work were agreed in advance, seek informed consent on the use of the data, offer reassurance on the anonymity of the data, set the rules of confidentiality among the group, let participants know that they could opt out at any point without having to explain why. This attempt to create a safe space for research participants during the FGDs and gain their trust also included avoiding direct questions on the use of 
mental health services, as direct questions might trigger uncomfortable memories of traumatic events and feelings which could have been difficult to contain in a research setting. Women who took part in the two FGDs were all regularly attending therapy groups and were used to discuss personal issues with each other and in a group setting. Their ages ranged from mid-twenties to early fifties, and the women were mainly of African origin the majority had to flee war in their home countries and arrived in London in the last ten years as asylum seekers. Given the sensitive nature of the research participants' experience and the fact that the research questions informing Elena's work had to necessarily inquiry into mental health in order to assess the extent to which women's community and voluntary organisations are able to cater for mental health service users, the use of art-informed FGD seemed most appropriate for this task.

4.14 In particular, collage making seemed rather straightforward as for instance it wouldn't emphasise different drawing skills within the groups. Butler-Kisber and Poldma (2010) trace a history of collage making as a form of artistic innovation developed in the $20^{\text {th }}$ century. This particular way of artistic expression has the peculiarity of using images which are uncoupled from the original context in which they were produced and are re-composed on a new plane, proposing a reading that disrupts the linearity of text. The non-linearity of collage making and the new context which is created in the collage has been compared to the 'interior shapes of mental space' and for this reason collage making is one of the privileged mediums for art therapists. Collage making was chosen as an art-based, non-textual form of representation which is able to elicit verbal explanations that alone might otherwise be narrow and not necessarily include broader life experiences. Rather than integrating visual analysis of the researcher's self-produced collage (as in Butler-Kisber \& Poldma 2010), in Elena's work collage making has the function to elicit personal stories about research participants' individual experiences of accessing mental health services. These personal stories were analysed thematically as narratives.

4.15 Collage making is a relational contextualising strategy produced by the research participants themselves rather than self-produced by the researcher/s and is therefore participatory. During the two FGDs women of refugee, asylum seeking and migrant background were asked to reflect on their journey and focus in particular on their experiences of accessing mental health services and subsequently were asked to compose a collage which reflects these experiences. Initially they were given some time with magazines, newspapers, scrap coloured paper, glitter and sequins, scissors and different types of glue. In this initial phase of the FGD research participants were interacting, communicating, laughing, helping each other while constructing their own story on an a cardboard panel. In the second phase of the FGD, participants were asked to explain what they had done and illustrate the images they had chosen for the collage. In Elena's mind, this should lead to a group discussion of the personal stories where the person describing the collage would speak and be listened by the rest of the group. As it turned out in both FGDs, only some of the participants felt they wanted to share their stories with the rest of the group. Although they did not make this clear by openly stating that they preferred not to speak up and share their story with the whole group, the tone of their voice, their body language and the fact that they were just talking to her suggested that they felt more comfortable with sharing their story of leaving their country of origin and accessing mental health services in the UK just with the researcher. Some other women in the FGDs felt like sharing with the rest of the group, however this, contrarily to Elena's initial expectations, did not lead to a group discussion, but just to listening in silence and expressing emotional support. Both FGDs have successfully engaged refugee, asylum seeking and migrant women in making a collage and reflecting on their own experiences of migration and access to mental health, however this did not lead to a group discussion as Elena had initially intended.

4.16 Elena used collage making as a heuristic tool informing experiential research approaches as she did not visually analyse the collage but instead used the participants' life stories as narratives elicited by the process of collage making. In the process she also considered which subject positions and situated knowledges are at play during the FGDs (see Vacchelli 2013 on feminist epistemology). In the approach Elena devised, the collage is an interpretive tool with the function of eliciting life stories in an open and participatory manner; its use is instrumental to qualitative data collection rather than the starting point for analysing visual data.

4.17 Yet whilst writing up her data analysis and while presenting at a recent conference it became apparent that the language of FGD was not enough to capture the complexity of what had happened during the creative FGDs with refugee and migrant women in London. For instance, collage making was the moment where most group interaction took place. Though, when research participants were asked to illustrate what they did, only some of the women felt like sharing this with the rest of the group. This unexpected one-to-one communication between research participant and moderator erased the key element of a FGD, i.e. the group 'discussion' itselfthis is the first disruption to the definition of the data collection method Elena used. Despite the fact that, in the FGD literature, the feature of 'discussion' is indeed central, the more flexible approach to FGD Elena used with 
her participants in London allowed them to opt out from the actual discussion. This flexibility is particularly useful for discussing sensitive issues as it allows for research participants to be in control of the way in which they want to express themselves and this situates the FGD in continuity with the data collection performed in the course of a WS.

4.18 Another way in which the FGD Elena conducted does not conform to the FGD literature is that for such particularly vulnerable group, dealing with highly sensitive issues such as trauma and mental health, verbal communication is not always the most suitable one: collage making provides more time to reflect what one wants to disclose; the selection of images allows for a more subconscious processing of what to expose. In addition, 'doing' as opposed to 'speaking' creates a more collaborative space where research participants ask others for help in locating certain images they need, make jokes and the overall register of the experience is more convivial if compared to a traditional FGD. In this sense, the kind of interaction which took place during the collage making FGDs is not as formalised as in the 'traditional' FG, i.e. the role of the moderator is not as central in keeping the group conversation going and the emphasis is more on the process than the flow of conversation. These features also contribute to situate the creative FGD in continuity with the WS method. With regards to second phase of the collage making FGD, the narratives elicited by the art-work do not necessarily need to be 'openedup' to the rest of group as the group was not necessarily discussing a particular topic of general interest as in the 'traditional' FGD and therefore the conversation flow between participants was not central and the creative FGD Elena devised met the objectives of eliciting personal narratives in a non-invasive manner starting from the creative group work. In this sense, the outcome of the data collection method Elena devised, framing it as a FGD, resembles more to a WS conducted outside a PAR setting although it was planned using theoretical frameworks and guidelines for the FGD.

\section{Theories in practice}

5.1 The approaches we both used consisted in deploying different prompts to stimulate views and various kinds of discussions among participants. In line with the recent performative turn in social sciences (Kamberelis \& Dimitriadis 2013), we argue, in certain kinds of research contexts researchers have to make decisions and adapt methods to better fit their research purposes. This holds several useful implications for future researchers which we outline in this section.

5.2 First, recognizing elements of continuity and difference between the two methods means acknowledging that the participatory features of art-informed FGDs align this data collection method with the WS where research participants are involved in group work, reflection, art-informed activities, visual elicitation. We devised our data collection approach as a FGD to make ourselves understood by the scientific community, but in hindsight we realized that the activities that we carried out present several continuities with the WS. The WS emerged within PAR as a tool for participation rather than as a data generating method and the way we devised our data collection placed a great emphasis on participation. Key distinctions between FGDs and WSs include that while the WS seeks general agreement among participants, the FGD aims mainly at eliciting discussion. Moreover, the WS uses several prompts to elicit debate among participants; this is done mostly through guidance and questioning by the moderator in FGD although there is increasing evidence that these approaches are now converging. Both methods aim to generate learning through every day interactions among participants, but they are intrinsically artificial as such interactions unfold in a space that would not have existed without the intervention of the researcher (Jowett \& O' Toole 2006).

5.3 Second, while WSs are explicitly aimed at reciprocal learning and at facilitating change of local circumstances either among participants or in relation with policy makers (Oreszcyn \& Carr 2008; Chambers 2002), Chiu (2003) argues that the FGD, in the context of PAR, has the potential to transform relations because it often engages with problem solving activities and critical reflections which would not be possible in a traditional power loaded research setting. Moreover, she adds that the FGD helps to explore participants' issues, and also it allows for them to take advantage of the space opened up by the focus group to discuss such issues (Chiu 2003). It could hence be argued that the FGD in the context of PAR is not that different from WS. The crucial difference between the two is the role played by the moderator/researcher. While in the FGD the researcher often directs questions to participants, stirs the discussion and is always present during their interaction, in the WS, due to the PAR context, the researcher becomes somehow a tool to initiate a discussion among participants, which are then left alone to continue their dialogue and to ultimately stir the debate within the bigger community they belong to (Oreszcyn \& Carr 2008; Stewart et al. 2007). Accordingly, researchers that employ FGDs are more interested in the verbal interaction among participants, which is often recorded or videotaped and transcribed, while when using the WS the focus is on the process itself and on reciprocal learning and the type of data generated consists of charts, maps and different types of visual representations (Stewart et al. 2007). Clearly, the question on the 
hybridization of the two methods arises when the FGD makes use of prompts and forms of elicitation in order to help stir the discussion during the focus group.

5.4 Third, both the experiences of Martina and Elena suggest that they developed their work having the FGD in mind and found themselves working with a method which resembles more the WS for the way in which the interaction with research participants in the field panned out. In Martina's case, the dynamic between participants and moderator reflected Chambers' statement (2002:133) 'empower the group and disempower yourself [moderator]'. Martina first sat in the back while participants discuss topics among themselves in a language she couldn't grasp with the help of two local facilitators, effectively leaving all the power to them and to participants to shape data gathering. Secondly, in the final discussion moment, she did not play an assertive role as a moderator, but rather she argued for participants' situated knowledge's value as opposed to technical knowledge, which she did not have herself.

5.5 In Elena's case, the creative FGD where art-making was used as elicitation of participants' narratives developed into a more participatory arena where action and participating in the proposed activity took a central position compared to the aspect of discussing in a group. Moreover, speaking in a group about personal issues relating to mental health, after the completion of the collage, was negotiated individually by the research participants and as a result the typical scenario of the FGD did not consistently take place. While the initial group activity during collage making was welcomed by everyone in the group, some participants chose not to disclose personal matters with the whole group when it came to discussing the meaning of the artwork they produced and this balancing out was made possible by the kind of flexibility offered by the creative FGD framework. This suggests that the boundaries of the traditional focus group need re-thinking when particular tasks and art-based activities are introduced.

5.6 Fourth, as mentioned above, we aimed at triggering dialogue among participants and between us and participants. In this sense, it has been argued in the literature that FGD can facilitate this type of interaction because it 'is a collectivistic rather than an individualistic research method that focuses on the multivocality of participants' attitudes, experiences, and beliefs' (Madriz 2000: 836), which thus avoids the more overtly hierarchical dynamic of a one-to-one interview. In FGDs, participants can facilitate each other's understanding of questions or challenge each other's answer, which an interviewer would rarely do in order to avoid intimidating the interviewee. FGD, according to feminist scholars, produce richer and more reliable data as it is already triangulated with several other participants (Montell 1999).

5.7 Fifth, both FDG and WS are functional to processes of knowledge construction among participants. The underlying difference between the processes initiated through these two methods is whether learning is happening. WS is a tool eminently directed towards reciprocal learning among participants, while the starting point for a FGD is the researcher's topic guide whose primary aim is to gather data and, secondly, to possibly create a space for knowledge construction among participants. While both methods engage participants in discussions and debates, it is not a given that new knowledge might originate during the FGD. On the other hand, WS is first and foremost a knowledge generating method.

5.8 It shouldn't however be forgotten that the FGD is an artificial attempt to recreate a natural interaction within a purposefully selected group by an external researcher/moderator that sets the lines and boundaries of discussion (Smithson 2008). Feminist scholars voice different concerns. While Montell (1999) refers to some work where the FGD acted as a means of empowerment and support for subordinated groups, Smithson (2008) cautions against the idealization of the liberating potential of this method. As Jowett and O'Toole (2006) she argues that the power over the analysis of data remains in the hand of researchers who can factually silence the voices of participants. The same happens in relation to participant's capability of influencing research aims. Montell (1999) claims that FGD can be key in influencing research aims and could potentially have an impact on the initial research questions, while Smithson (2008) highlights that the power remains in the hand of the researcher that can ultimately decide if and how to convey the narratives of oppressed groups. The moderator plays an important role in this, by potentially influencing the type of data generated due to bias against certain participants or topics. Moreover, focus groups are not inherently participatory as some voices might prevail over others and achieving consensus can inherently counteract multivocality as we have argued above (Baker \& Hinton 1999).

5.9 Finally, the range of potential advantages and limitations of the FGD method points to the fact that communication in FGD is often exclusively based on interactive talk. As such, from a feminist epistemological point of view, it might not be suitable for vulnerable groups or for dealing with personal or sensitive issues, while 
a more activity-based approach as in the WS could help overcome these limitations. When it comes to participants in vulnerable situations or when the positionality between research and research participants suggests deep class, gender, age, ethnic, educational background differences, a more participatory, activityoriented approach, as found in the WS, is often a more suitable approach than the more prescriptive framework of the FGD. Because of our feminist epistemological standpoint, we used the jargon and academic literature repertoire linked to FGD but effectively set up a process consisting in elicitation activities and triggers that tend to chime more with the definition of WS.

5.10 Yet we acknowledge that the ways in which learning is produced and shared during FGDs is different from the learning process sparked by the WS. For instance, FGDs are designed as a means of gathering data and addressing specific research question for the researcher's purpose, while WSs are not designed to collect qualitative data as such, but rather (in the context of PAR) to involve participants in the determination of research priorities and to share knowledge among participants with the aim of initiating a reflexive process on their everyday practices. The question missing from the qualitative research literature is what happens when the WS is conducted in contexts situated outside the PAR framework and when the FGD incorporates activity-based work to elicit the group discussion. While some literature has indeed discussed potentials and limitations of art and activity based FGDs (Cooper \& Yarbrough 2010; Colucci 2007) this specific question has not been asked before.

\section{Concluding remarks}

6.1 This paper has drawn on the authors' individual research experiences in East Africa and in London to reflect on the boundaries of the FGD and on the continuity and disjuctions between the FGD and the WS in the current academic discourse around qualitative research methods. The experiences both Martina and Elena during their fieldwork confirm that the research design and conceptual apparatus they devised to collect qualitative data does not fall within the narrow boundaries dictated by the current definition of FGD within the academic literature on qualitative research methods and that this needs to be extended to incorporate creative and activity-based FGDs. While critically assessing the limits of the FGD as a legitimate data collection method, it became evident that in order to report on their fieldwork they had to acknowledge the continuity existing between what they did and the WS. Current academic literature on the WS however is confined to the PAR field and the WS as a qualitative research method outside PAR does not seem to have acquired the same level of attention let alone legitimacy as the FGD has. WSs in the context of PAR are in fact, according to Kapoor (2002) undertheorized and ascribed to an un-theoretical, prevalenty practice orientation. Kapoor also (2002) reminds us that the WS was not originally devised as a data generating method, but rather as a tool for reciprocal learning.

In the light of our experiences during fieldwork in East Africa and London, our work points towards the need for further engagement with the WS as a data geneating method outside the context of PAR. As highlighted by ours and other recent attempts to weigh the potentials and limitations of FGDs that make an increasing use of various creative, elicitation and activity-oriented techniques, (and thus deploying features that are normally ascribed to the WS rather than the FGD) it is evident that the WS allows for a greater level of flexibility where research participants are given more control in driving the modes of interaction during the FGD. This is evident from Elena's case and is particularly helpful when working with people in vulnerable situations such as research participants who regularly access mental health services. In Martina's case, the use of a series of activities during the focus group as social learning tool has allowed rural research participants to exchange views around irrigation and other agricultural practices. This kind of exchange encompassing actions, strategies and practices would have been more difficult in the context of a moderated conversation flow during a conventional FGD and the hybridisation of the FGD has allowed for these negotiations to happen with less interventions by the researcher. The blending of these two methods mirrors our feminist research ethics and specifically our conviction that researchers do not empower research participants, but rather participants are endowed of the power to withhold information and to use the data gathering instances as useful moment of knowledge construction for their local realities (see also Janes 2015).

6.3 Like other authors (Colucci 2007; Cooper \& Yarbrough 2010; Silverman 2013) we used the jargon and academic literature repertoire linked to the FGD but effectively choose prompts and activities that tend to chime more with the definition of the WS. This further demonstrates that more work is needed to define the WS as a legitimate qualitative data collection tool which can be used in several research contexts and not just in PAR. In problematizing the boundaries of FGD and recognizing the influence of WS oriented methods in current developments of qualitative research across the social sciences, we argue that the boundaries of the FGD should be re-examined and more methodological research should be carried out on the WS as a legitimate 


\section{Footnote}

workshop I a place where things are made or repaired. (n.d.). Retrieved March 31, 2015, from http://www.merriam-webster.com/dictionary/workshop.

\section{Funding Acknowledgements}

Caretta's field study (research authorizations: TZ: PF/IRA.15; KE: NCST/RDC/10/013/16) was carried out thanks to the financial support of the Swedish International Cooperation Agency (SWE2009-210). Principal research partners in the field were Florence Cheptum, Timothy Kipkeu and Helena Chepto in Kenya and Catherine Molel in Tanzania. The financial support to conduct Dr Elena Vacchelli's research is from the Fundamental Rights Agency in Vienna. The research in London was carried out as a local impact study from a larger study which took place in 2011-12 - Inequality and Multiple Discrimination in Access to and Quality of Healthcare Middlesex University was the coordinating team of a 5 country European research including the UK. It involved documentary review of UK policies, development of methodology for qualitative and quantitative analysis; interviews with several categories of hard to reach and vulnerable groups, including young minority ethnic people with disabilities and older ethnic minorities.

\section{References}

BAKER, R., \&and Hinton, R. (1999). Do focus groups facilitate meaningful participation in social research? In Barbour S.R. \& J. Kitzinger (Eds.) Developing Focus Group Research United Kingdom: SAGE Publications Ltd. p. 79-98.

BARBOUR, R. and\& Flick, U. (2007). Doing focus groups. Thousand Oaks, Calif.: Sage Publications.

BUTLER-KISBER, L. and T. Poldma 'The Power of Visual Approaches in Qualitative Inquiry: The Use of Collage Making and Concept Mapping in Experiential Research' Journal of Research Handbook of Social Research Methods. SAGE, p.356-371.

CALLAGHAN, G. (2005) ' Accessing habitus: relating structure and agency through focus group research' Sociological Research Online 10 (3) http://www.socresonline.org.uk/10/3/callaghan.html. [doi:10.5153/sro.1129]

CAMBRIDGE DICTIONARY (2015) workshop definition, meaning - what is workshop in the British English Dictionary \& Thesaurus - Cambridge Dictionaries Online. Retrieved March 31, 2015, from http://dictionary.cambridge.org/dictionary/british/workshop.

CARETTA, M. A. (2014). Hydropatriarchies and landesque capital: a local gender contract analysis of two smallholder irrigation systems in East Africa. The Geographical Journal, n/a-n/a. http://doi.org/10.1111/geoj.12102.

CARETTA, M. A. (2015). Situated knowledge in cross-cultural, cross-language research: a collaborative reflexive analysis of researcher, assistant and participant subjectivities. Qualitative Research, 15(4), p.489-505. http://doi.org/10.1177/1468794114543404 [doi:10.1177/1468794114543404]

CARETTA, M. A. and\& Börjeson, L. (2015). Local gender contract and adaptive capacity in smallholder irrigation farming: a case study from the Kenyan drylands. Gender, Place \& Culture, 22(5), p. 644-661. http://doi.org/10.1080/0966369X.2014.885888 [doi:10.1080/0966369X.2014.885888]

CATTERALL, M. and Maclaran, P. (1997) 'Focus Group Data and Qualitative Analysis Programs: Coding the Moving Picture as Well as the Snapshots' Sociological Research Online, 2 (1). 
CHAMBERS, R. (2002). Participatory workshops?: a sourcebook of 21 sets of ideas and activities London: Earthscan.

CHIU, L. F. (2003). Transformational Potential of Focus Group Practice in Participatory.Action Research, 1(2), p.165-183. doi:10.1177/14767503030012006. [doi:10.1177/14767503030012006]

COOPER, Cheryl M., and Susan P. Yarbrough. "Tell me-show me: Using combined focus group and photovoice methods to gain understanding of health issues in rural Guatemala." Qualitative Health Research (2010).

COLUCCI, E. (2007). "Focus groups can be fun": The use of activity-oriented questions in focus group discussions. Qualitative Health Research, 17(10), p.1422-1433. [doi:10.1177/1049732307308129]

HENNINK, M. M. (2008). Emergent issues in international focus group discussions. Handbook of Emergent Methods, p.207-220.

JAKOBSEN, H. (2012). Focus groups and methodological rigour outside the minority world: making the method work to its strengths in Tanzania. Qualitative Research, 12(2), p.111-130. doi:10.1177/1468794111416145. [doi:10.1177/1468794111416145]

JANES, J.E. (2015). Democratic encounters? Epistemic privilege, power, and community-based participatory. Action Research. Online first. doi:10.1177/1476750315579129. [doi:10.1177/1476750315579129]

JOWETT, M. and\& O'Toole, G. (2006). Focusing researchers' minds: contrasting experiences of using focus groups in feminist. Qualitative Research, 6(4), p.453-472. doi:10.1177/1468794106068014. [doi:10.1177/1468794106068014]

KAMBERELIS, G., \& Dimitriadis, G. (2013). Focus groups?: from structured interviews to collective conversations. Abingdon, Oxon?; Routledge.

KAPOOR, I. (2002). The devil's in the theory: A critical assessment of Robert Chambers' work on participatory development. Third World Quarterly, 23(1) p.101117. http://doi.org/10.1080/01436590220108199. [doi:10.1080/01436590220108199]

KITZINGER, J. (1994) 'The Methodology of Focus Groups: The Importance of Interaction Between Research Participants', Sociology of Health and IIIness 16(1) p.103-21 [doi:10.1111/1467-9566.ep11347023]

KRUEGER, R. A., \& Casey, M. A. (2008).Focus Groups: A Practical Guide for Applied Research SAGE Publications.

LABRA, I. and Labra, I. (n.d.) ' The organizational workshop method. Laboratories on the objectivized activity" Integra Terra Network. Seriti Institute: Johannesburg, SA. Retrieved Retrieved July 30, 2015, from http://www.seriti.org.za/phocadownloadpap/OW/OW\%20Method\%20Laboratories.pdf

LIAMPUTTONG, P. (2011). Focus group methodology?: principles and practice. [S.I.]: Sage Publications Ltd.

MADRIZ, E. (2000). Focus groups in feminist research. In Denzin, N. K., Lincoln, Y. S., \& Lincoin, Y. S. (Eds.) Handbook of Qualitative Research. Thousand Oaks, Calif: Sage Publications, Inc.2, p. 835-850.

MARKOVÁ, Ivana, Per Linell, Michèle Grossen, and Anne Salazar Orvig. (2007) Dialogue in Focus Groups?: Exploring in Socially Shared Knowledge. Studies in Language and Communication. London: Equinox Publishing.

MERRIAM WEBSTER (2015) Workshop I a place where things are made or repaired. Retrieved March 31, 2015, from http://www.merriam-webster.com/dictionary/workshop.

MERRYWEATHER, Dave. (2010). Using Focus Group Research in Exploring the Relationships Between Youth, Risk and Social Position. Sociological Research Online, 15(1). http://doi.org/10.5153/sro.2086. [doi:10.5153/sro.2086]

MONTELL, F. (1999). Focus Group Interviews: A New Feminist Method.NWSA Journal, 11(1), p.44-71. [doi:10.2979/NWS.1999.11.1.44]

MORGAN, D. L. (1997). The Focus Group Guidebook. SAGE. 
MORGAN, D., Fellows, C., \& Guevara, H. (2008). Emergent approaches to focus group research.Handbook of Emergent Methods, p.189-205.

MOSCHITZ, H., and\& Home, R. (2014). The challenges of innovation for sustainable agriculture and rural development: Integrating local actions into European policies with the Reflective Learning Methodology. Action Research, 12(4) p.392-409. doi:10.1177/1476750314539356. [doi:10.1177/1476750314539356]

ORESZCZYN, S. and \& Carr, S. (2008). Improving the link between policy research and practice: using a scenario workshop as a qualitative research tool in the case of genetically modified crops. Qualitative Research, 8(4) p.473-497. doi:10.1177/1468794107087479. [doi:10.1177/1468794107087479]

REID, C. and \& Frisby, W. (2008). 6 Continuing the Journey: Articulating Dimensions of Feminist Participatory Action Research (FPAR). In P. Reason \& H. Bradbury, The SAGE Handbook of Action Researchp. 93105. 1 Oliver's Yard, 55 City Road, London England EC1Y 1SP United Kingdom: SAGE Publications Ltd.

SILVERMAN, D. (2013) Interpreting qualitative data. London: Sage Publications

SMITHSON, J. (2008) Focus group. in Alasuutari, P., Bickman, L., \& Brannen, J. (eds). The SAGE Handbook of Social Research Methods London: Sage p.357-370 [doi:10.4135/9781446212165.n21]

STEWART, D. W., Shamdasani, P. N., \& Rook, D. W. (2007).Focus groups: theory and practice. Thousand Oaks, Calif.: Sage Publications.

VACCHELLI, E. (2013) 'Researching the urban reflexively: feminist methodological issues' Hagar: studies in culture, polities and identities 11(1) p.41-62

VACCHELLI, E. and S.Menzies (2015) 'Assessing community-based mental health services for migrant, refugee and asylum seeking women. A participatory approach. SPRC and EOU Report, November (forthcoming)

VACCHELLI, E. (2016) 'Embodiment as qualitative research: collage-making with migrant, refugee and asylum seeking women' Qualitative Research (forthcoming)

WILKINSON, S. (1998). Focus groups in feminist research: Power, interaction, and the co-construction of meaning. In Women's studies international forum Vol. 21, p.111-125. Elsevier. [doi:10.1016/S02775395(97)00080-0]

WILKINSON, S. (1999). How useful are focus groups in feminist research? In Barbour S.R. \& J. Kitzinger (Eds.)Developing Focus Group ResearchSAGE Publications Ltd. p.64-78. 